\title{
Design optimization of cold-formed steel portal frames taking into account the effect of building topology
}

\author{
Duoc T. Phan ${ }^{\mathrm{a}}$, James B.P. Lim*, Wei Sha ${ }^{\mathrm{a}}$, Calvin Y.M. Siew ${ }^{\mathrm{b}}$, Tiku T. Tanyimboh ${ }^{\mathrm{b}}$, \\ Honar K. Issa ${ }^{\mathrm{c}}$ and Fouad A. Mohammad ${ }^{\mathrm{c}}$ \\ ${ }^{a}$ SPACE, Queen's University, Belfast, UK; ${ }^{b}$ Department of Civil Engineering, The University of \\ Strathclyde, Glasgow, UK; ${ }^{c}$ School of Architecture, Design and Built Environment, Nottingham Trent \\ University, Nottingham, UK
}

(Received 16 May 2011; final version received 18 February 2012)

\begin{abstract}
Cold-formed steel portal frames are a popular form of construction for low-rise commercial, light industrial and agricultural buildings with spans of up to $20 \mathrm{~m}$. In this article, a real-coded genetic algorithm is described that is used to minimize the cost of the main frame of such buildings. The key decision variables considered in this proposed algorithm consist of both the spacing and pitch of the frame as continuous variables, as well as the discrete section sizes. A routine taking the structural analysis and frame design for cold-formed steel sections is embedded into a genetic algorithm. The results show that the real-coded genetic algorithm handles effectively the mixture of design variables, with high robustness and consistency in achieving the optimum solution. All wind load combinations according to Australian code are considered in this research. Results for frames with knee braces are also included, for which the optimization achieved even larger savings in cost.
\end{abstract}

Keywords: cold-formed steel; portal frames; building topology; real-coded genetic algorithm

\section{Introduction}

The majority of portal frames use conventional hot-rolled steel sections for the primary loadcarrying members (i.e. columns and rafters) and cold-formed steel for the secondary members (i.e. purlins, side rails and cladding). Using hot-rolled steel, spans of up to $60 \mathrm{~m}$ can be achieved. For frames of more modest spans, the use of cold-formed steel for the primary load-carrying members (i.e. . columns and rafters) should be an alternative to conventional hot-rolled steel.

However, because fabrication and erection costs for cold-formed steel are much lower than for hot-rolled steel, there is scope to vary the frame spacing and pitch. Other advantages of coldformed steel frames compared to hot-rolled steel are as follows. Pregalvanized cold-formed steel sections that do not require painting to prevent rusting are maintenance free. The transportation costs are lower owing to efficient stacking of cold-formed steel sections. Also, the acquisition costs are lower as the cold-formed steel used for the secondary members can be purchased from the same manufacturer/supplier.

*Corresponding author. Email: j.lim@qub.ac.uk

ISSN 0305-215X print/ISSN 1029-0273 online

(C) 2012 Taylor \& Francis

http://dx.doi.org/10.1080/0305215X.2012.678493

http://www.tandfonline.com 


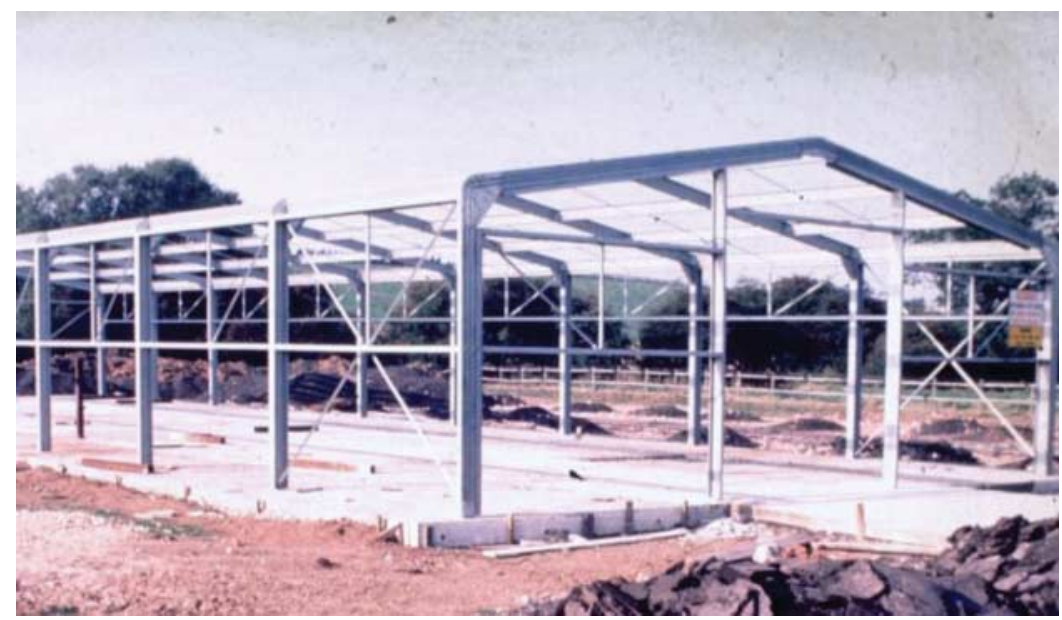

Figure 1. Cold-formed steel portal framing system.

Cold-formed steel portal frames (Figure 1) are a popular form of construction in Australia and the UK. They are commonly used for low-rise commercial, light industrial and agricultural buildings with spans of up to $20 \mathrm{~m}$. For such frames, moment-resisting joints at the eaves and apex can be formed through mechanical interlock (Figure 2a). As can be seen from Figure 2(a), the joints are formed through brackets that are bolted to the webs of the channel-sections. Under moment, the matching swages in both the brackets and the webs of the channel-sections interlock, thus forming a rigid joint (Kirk 1986). With longer span frames, to reduce the section sizes of both the column and rafter members, a knee brace is often included at the eaves (Figure 2b). The effect of including a knee brace is that the bending moment that needs to be resisted by both the column and rafter around the joint is reduced, with the axial load carried through the knee brace (Rhodes and Burns 2006).

Over the past three decades, the design optimization of structures has attracted much attention from researchers (Kuhn and Tucker 1951, Moses 1964, Allwood and Chung 1984, Erbatur and Al-Hussainy 1992, Gero et al. 2005). Many structural engineering design problems have discrete decision variables. For instance, in the design of steel frames, the cross-sectional sizes of the columns and rafters are selected from standard tables. One of the most efficient methods for solving complex combinatorial optimization problems such as the design of steel portal frames is genetic algorithms (GAs), based on the Darwinian principle of survival of the fittest and adaptation (Holland 1975, Goldberg 1989).

Binary-coded GAs have been applied to the design of hot-rolled steel frames to find the discrete cross-sectional sizes for the members that minimize the weight of the structure (Chen and Chen 1997, Kameshki and Saka 2001, Toropov and Mahfouz 2001, Gero et al. 2006). However, one of the limitations of binary-coded GAs is the extra computational complexity of the algorithm associated with continuous decision variables (Deb 2001). Therefore, real-coded GAs (Wright 1991, Michalewicz 1992, Ono and Koframeashi 1997, Deb 2001, Deb and Gulati 2001) were proposed to resolve the drawback of binary-coded GAs.

In design optimization of hot-rolled steel portal frames, Saka (2003) described a binary-coded genetic algorithm to minimize the weight of a portal frame through selecting the most appropriate hot-rolled steel section sizes for the columns and rafters, from a catalogue of available standard sections, based on elastic analysis and design as described in the British Standards (BS 5950-1). More recently, Issa and Mohammad (2010) described a genetic algorithm using binary strings, to study the same problem. They varied the length and depth of the haunched part of the rafter in 


$$
{ }_{r}^{r}
$$


optimization of cold-formed steel portal frames with either fixed or variable topology has not been considered previously. In this article, a genetic algorithm is proposed to minimize the cost of cold-formed steel portal frame buildings by minimizing the cost of the main structural elements per unit length of the building. Although any code of practice can be used the Australian code was adopted, rather than the UK code, since in Australia the spans of the frames can be larger as there is less snow.

The optimization method proposed addresses all the relevant combinations of the permanent and imposed loads, incorporates the full range of design constraints and considers all feasible wind load combinations. It is assumed here that full lateral restraint is applied to columns and rafters. It is also assumed that the cost of the purlins, side rails and sheeting is independent of frame spacing. The present research differs from previous work on hot-rolled steel portal frames in that the crosssectional sizes of the columns and rafters and the topology of the building, including the pitch and frame spacing, are all jointly optimized simultaneously. The decision variables used in the design optimization are the spacing of the frames; the pitch of the roof ;nd the cross-sectional sizes of the main structural elements. Self-evidently, the solution space has both discrete and continuous variables. Unlike in previous research on hot-rolled steel frames that used binary coding for the genetic algorithm, real coding is used here.

\section{Frame descriptions}

\subsection{Frame parameters}

Figure 3 shows the parameters used to define both a rigid-jointed cold-formed steel portal frame (Figure 3a) and a rigid-jointed cold-formed steel portal frame having knee braces at the eaves
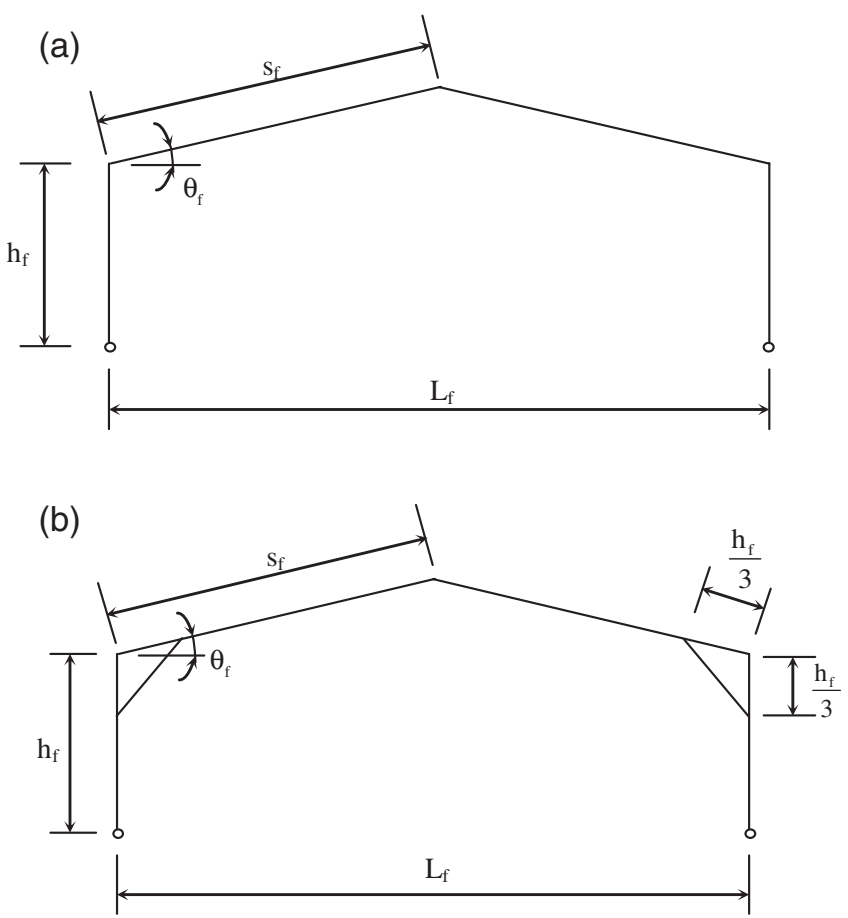

Figure 3. Geometries of cold-formed steel portal frames: (a) Frame A: rigid-jointed frame; (b) Frame B: rigid-jointed frame having knee braces at the eaves. 
(a)

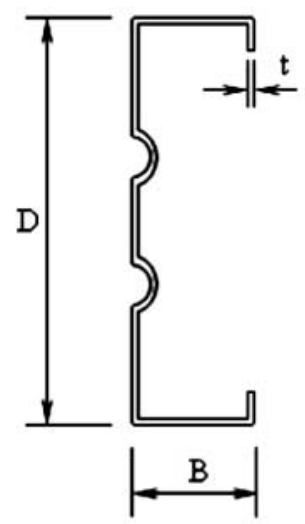

(b)

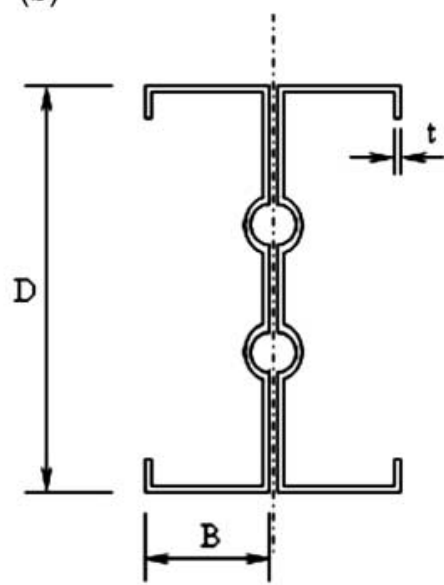

Figure 4. Details of cold-formed steel channel-section: (a) single channel-section (C-section); (b) back-to-back channel-section (BBC).

Table 1. Dimensions and section properties of cold-formed steel sections.

\begin{tabular}{|c|c|c|c|c|c|c|c|}
\hline Section & $D(\mathrm{~mm})$ & $B(\mathrm{~mm})$ & $t(\mathrm{~mm})$ & $E A\left(\times 10^{2}\right)(\mathrm{kN})$ & $E I\left(\times 10^{6}\right)\left(\mathrm{kN} \cdot \mathrm{mm}^{2}\right)$ & Weight $(\mathrm{kg} / \mathrm{m})$ & Cost $(\mathrm{A} \$ / \mathrm{m})$ \\
\hline C10010 & 102 & 51 & 1.0 & 451.0 & 73.8 & 1.78 & 5.58 \\
\hline C10012 & 102 & 51 & 1.2 & 533.0 & 88.2 & 2.10 & 6.15 \\
\hline C10015 & 102 & 51 & 1.5 & 656.0 & 110.7 & 2.62 & 6.77 \\
\hline C10019 & 102 & 51 & 1.9 & 840.5 & 137.4 & 3.29 & 8.37 \\
\hline C15010 & 152 & 64 & 1.0 & 604.8 & 225.5 & 2.32 & 7.03 \\
\hline C15012 & 152 & 64 & 1.2 & 717.5 & 264.5 & 2.89 & 7.99 \\
\hline C15015 & 152 & 64 & 1.5 & 902.0 & 330.1 & 3.59 & 8.46 \\
\hline C15019 & 152 & 64 & 1.9 & 1148.0 & 414.1 & 4.51 & 10.52 \\
\hline C15024 & 152 & 64 & 2.4 & 1455.5 & 520.7 & 5.70 & 12.88 \\
\hline $\mathrm{C} 20012$ & 203 & 76 & 1.2 & 922.5 & 574.0 & 3.50 & 8.99 \\
\hline C20015 & 203 & 76 & 1.5 & 1148.0 & 723.7 & 4.49 & 10.04 \\
\hline C20019 & 203 & 76 & 1.9 & 1455.5 & 924.6 & 5.74 & 12.56 \\
\hline $\mathrm{C} 20024$ & 203 & 76 & 2.4 & 1845.0 & 1166.5 & 7.24 & 15.29 \\
\hline $\mathrm{C} 25015$ & 254 & 76 & 1.5 & 1312.0 & 1250.5 & 5.03 & 13.66 \\
\hline $\mathrm{C} 25019$ & 254 & 76 & 1.9 & 1660.5 & 1562.1 & 6.50 & 14.43 \\
\hline C25024 & 254 & 76 & 2.4 & 2091.0 & 1972.1 & 8.16 & 17.82 \\
\hline С30019 & 300 & 96 & 1.9 & 2070.5 & 2788.0 & 7.92 & 22.76 \\
\hline C30024 & 300 & 96 & 2.4 & 2583.0 & 3485.0 & 10.09 & 29.52 \\
\hline C30030 & 300 & 96 & 3.0 & 3280.0 & 4366.5 & 12.76 & 36.25 \\
\hline C35030 & 350 & 125 & 3.0 & 3915.5 & 7339.0 & 15.23 & 44.74 \\
\hline
\end{tabular}

(Figure 3b). These parameters are as follows: span of frame $L_{f}$, height to eaves $h_{f}$, length of rafter $s_{f}$, pitch of frame $\theta_{f}$, flexural rigidity of members $E I$, axial rigidity of members $E A$ and frame spacing $b_{f}$. For the case of portal frames having knee braces at the eaves, the positions of the knee braces are fixed relative to $h_{f}$, as shown in Figure 3(b).

Figure 4 shows the dimensions of the cold-formed steel channel-sections used for the primary load-carrying members in portal frame buildings. Table 1 shows the cold-formed steel channelsections used in this article. These channel-sections can be used either singly or back to back. The swages on the web of channel-sections improve the load-carrying capacity of the members. However, it should be noted that in order to simplify the checking procedure and to obtain a conservative design, the section properties and member checks are based on plane channel-sections and therefore ignore the benefit of the swages. 


\subsection{Frame geometry}

In this article, the design optimization of two exemplar frames with $L_{f}$ of $20 \mathrm{~m}$ and $h_{f}$ of $4 \mathrm{~m}$ is considered: Frame A, without knee braces (Figure 3a), and Frame B, with knee braces (Figure 3b). To minimize the cost per unit length of the building, the decision variables are the pitch, frame spacing and cross-section sizes of the members.

It is assumed that the column bases are pinned, and that the purlins and side rails positioned within the web of the members are spaced sufficiently close $e_{\AA}$ ach other to prevent out-of-plane buckling from occurring.

\subsection{Frame loading}

\subsubsection{Permanent and imposed roof loads}

The permanent and imposed roof loads (AS/NZS 1170-1 2002b) that will be applied to the frames are as follows:

- permanent load $(G): 0.10 \mathrm{kN} / \mathrm{m}^{2}$ (purlins, rails, cladding) and self-weight of the members (Table 1)

- imposed load $(Q): 0.25 \mathrm{kN} / \mathrm{m}^{2}$.

\subsubsection{Wind loads}

From the Australian Standard code of practice on wind loading for the design of buildings (AS/NZS 1170-2 2002c), the basic wind pressure $q_{u}$ for the ultimate limit state is calculated from a design wind speed $V_{\text {des }}$, which in turn is calculated from the regional wind speed $V_{R}$ multiplied by factors $M_{d}$ (wind direction multiplier), $M_{z, c a t}$ (terrain/height multiplier), $M_{s}$ (shielding multiplier) and $M_{t}$ (topographic multiplier). It is worth noting that $M_{z, c a t}$ depends on both the terrain category and the average height of the building.

For example ${ }_{2}$ Frame A, with dimensions as shown in Figure 5, built in the wind region $W$ in Australia with $V_{R}$ of $49.4 \mathrm{~m} / \mathrm{s}$, the multiplier factors of $M_{d}, M_{t}$ and $M_{s}$ are taken as 1.0 and $M_{z, \text { cat }}$ ef 0.87 . The design wind speed is calculated as follows:

$$
V_{\text {des }}=V_{\text {site }}=V_{R} \cdot M_{d} \cdot\left(M_{t} \cdot M_{s} \cdot M_{z, c a t}\right)=42.98 \mathrm{~m} / \mathrm{s}
$$

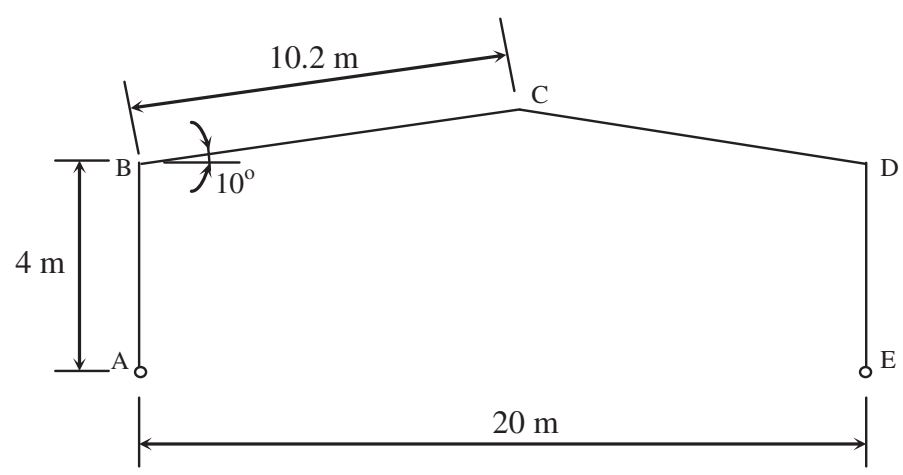

Figure 5. Dimensions of frame. 
where $V_{\text {site }}$ is the site wind speed and $V_{\text {des }}$ is the design wind speed; and the basic wind pressure:

$$
q_{u}=\frac{0.6 \times V_{d e s}^{2}}{1000}=1.1 \mathrm{kN} / \mathrm{m}^{2}
$$

where $q_{u}$ is the ultimate design wind pressure.

The design wind pressure acting on each of the four faces of the frame $(\mathrm{AB}, \mathrm{BC}, \mathrm{CD}$ and $\mathrm{DE}$ ) is obtained by multiplying $q_{u}$ by a coefficient of pressure and other related factors. The coefficient of pressure acting on each face is obtained from a combination of the external pressure coefficient $C_{p e}$ and the internal pressure coefficient $C_{p i}$. The external pressure coefficients $C_{p e}$ should be calculated for wind acting on the side and on the end. These values are shown in Table 2, calculated based on AS/NZS 1170-2 (2002c).

For buildings of normal permeability without dominant openings, $C_{p i}$ has a minimum value of -0.3 for suction and a maximum value of 0.2 for pressure.

The eight wind load combinations for Frame A (WLC1 to WLC8), and their corresponding coefficients for both side wind and end wind, are shown in Table 3. The coefficients of pressures $C_{p e}$ given by WLC1 are illustrated in Figure 6. As can be seen, the frame will be checked for all eight wind load combinations in the design procedure to be described in Section 2.5.

Table 2. Coefficients of external pressure $C_{p e}$.

\begin{tabular}{lllll}
\hline & \multicolumn{4}{c}{ Coefficient $C_{p e}$ on face } \\
\cline { 2 - 5 } Description & $\mathrm{AB}$ & $\mathrm{BC}$ & $\mathrm{CD}$ & $\mathrm{DE}$ \\
\hline Wind acting on side of frame (WT1) & 0.7 & -0.3 & -0.3 & -0.3 \\
Wind acting on side of frame (WT2) & 0.7 & -0.7 & -0.3 & -0.3 \\
Wind acting on end of frame (WL1) & -0.65 & -0.9 & -0.9 & -0.65 \\
Wind acting on end of frame (WL2) & -0.2 & 0.2 & 0.2 & -0.2 \\
\hline
\end{tabular}

Table 3. Coefficients of pressure $\left(C_{\mathrm{pe}}+C_{\mathrm{pi}}\right)$ corresponding to different wind load cases.

\begin{tabular}{llcccc} 
& & \multicolumn{4}{c}{ Coefficient on face } \\
\cline { 3 - 6 } Wind load combination & \multicolumn{1}{c}{ Description } & AB & BC & CD & DE \\
\cline { 3 - 6 } WLC1 & Wind on side + internal pressure & $0.7+0.2$ & $-0.3+0.2$ & $-0.3+0.2$ & $-0.3+0.2$ \\
WLC2 & Wind on side + internal suction & $0.7-0.3$ & $-0.3-0.3$ & $-0.3-0.3$ & $-0.3-0.3$ \\
WLC3 & Wind on side + internal pressure & $0.7+0.2$ & $-0.7+0.2$ & $-0.3+0.2$ & $-0.3+0.2$ \\
WLC4 & Wind on side + internal suction & $0.7-0.3$ & $-0.7-0.3$ & $-0.3-0.3$ & $-0.3-0.3$ \\
WLC5 & Wind on end + internal pressure & $-0.65+0.2$ & $-0.9+0.2$ & $-0.9+0.2$ & $-0.65+0.2$ \\
WLC6 & Wind on end + internal suction & $-0.65-0.3$ & $-0.9-0.3$ & $-0.9-0.3$ & $-0.65-0.3$ \\
WLC7 & Wind on end + internal pressure & $-0.2+0.2$ & $0.2+0.2$ & $0.2+0.2$ & $-0.2+0.2$ \\
WLC8 & Wind on end + internal suction & $-0.2-0.3$ & $0.2-0.3$ & $0.2-0.3$ & $-0.2-0.3$ \\
\hline
\end{tabular}

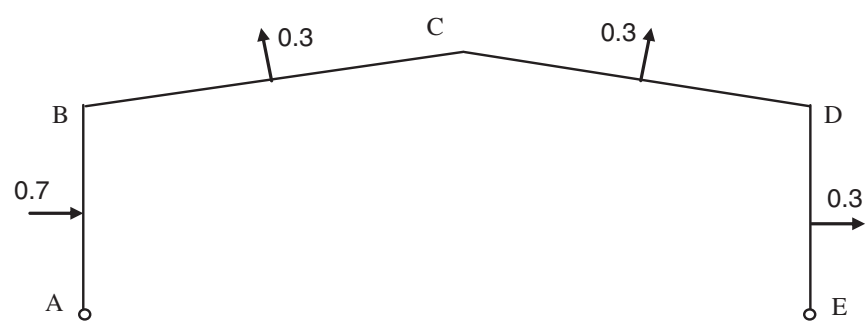

Figure 6. Coefficients of wind pressure for wind load combination 1 (WLC1) for standard frame. 


\subsubsection{Limit state design}

In accordance with AS/NZS 1170-0 (2002a), the frame will be checked at the ultimate limit state for the following three ultimate load combinations:

$$
\begin{aligned}
\text { ULC1 } & =1.2 G+1.5 Q \\
\text { ULC2 } & =1.2 G+W L C \\
\text { ULC3 } & =0.9 G+W L C
\end{aligned}
$$

It should be noted that ULC3 is used for the uplift wind load combination.

\subsection{Frame analysis}

A first order elastic frame analysis program, written by the authors for cold-formed steel sections, referred as LGSFrame, is used to analyse and design the portal frame. To take into account second order effects, an amplification factor is applied as described in the Australian code of practice. For each load combination, the bending moment, shear force and axial force are determined. LGSFrame is called to analyse each candidate solution in each generation as shown in Figure 7.

\subsection{Member checks}

\subsubsection{Columns and rafters}

In accordance with AS/NZS 4600 (2005), the columns and rafters are checked for combined axial compression and bending, distortional buckling, and combined bending and shear.

The combined axial compression and bending check is:

$$
\frac{N_{k}^{*}}{\phi_{c} N_{s}^{k}}+\frac{M_{x k}^{*}}{\phi_{b} M_{b x}^{k}} \leq 1
$$

where $N_{s}^{k}$ is the nominal section capacity of member $k$ in compression, $M_{b x}^{k}$ is the nominal member moment capacity of member $k$ about the $x$-axis, $N_{k}^{*}$ is the design axial compression in member $k$, $M_{x k}^{*}$ is the design bending moment in member $k$ about the $x$-axis of the effective cross-section, $\phi_{c}$ is the capacity reduction factor for compression, and $\phi_{b}$ is the capacity reduction factor for bending.

The distortional buckling check is:

$$
M_{x k}^{*} \leq \phi_{b} M_{b x}^{k}
$$

with $M_{b x}^{k}=Z_{c} f_{c}$ and $f_{c}=M_{c} / Z_{f}$; where $M_{x k}^{*}$ is the design bending moment in member $k$ about the $x$-axis of the effective cross-section, $\phi_{b}$ is the capacity reduction factor for bending, $M_{b x}^{k}$ is the nominal member moment capacity of member $k, Z_{\mathrm{c}}$ is the effective modulus at a stress $f_{\mathrm{c}}$ in the extreme compression fibre, $M_{c}$ is the critical moment, and $Z_{f}$ is the full unreduced section modulus for the extreme compression fibre.

The combined bending and shear check is:

$$
\frac{M_{x k}^{*}}{\phi_{b} M_{s}^{k}}+\frac{V_{k}^{*}}{\phi_{v} V_{v k}} \leq 1
$$

where $M_{s k}^{*}$ is the design bending moment in member $k$ about the $x$-axis of the effective crosssection, $M_{s}^{*}$ is the nominal section moment capacity of member $k$ about the $x$-axis, $V_{k}^{*}$ is the design shear force in member $k, V_{v k}$ is the nominal shear capacity of the web of member $k, \phi_{b}$ is the capacity reduction factor for bending, and $\phi_{v}$ is the capacity reduction factor for shear. 
401

402

403

404

405

406

407

408

409

410

411

412

413

414

415

416

417

418

419

420

421

422

423

424

425

426

427

428

429

430

431

432

433

434

435

436

437

438

439

440

441

442

443

444

445

446

447

448

449

450

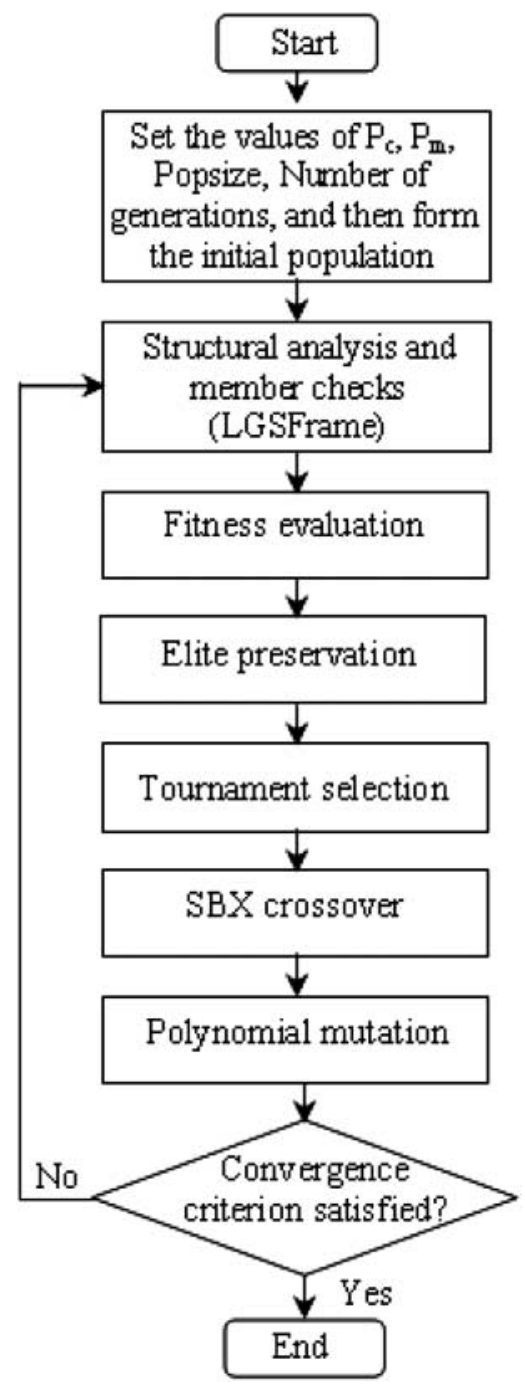

Figure 7. Flowchart of the real-coded GA.

\subsubsection{Eaves knee braces}

The knee brace is a pin-ended member and is checked for both compression and tension. The compression check is:

$$
N_{k}^{*} \leq \phi_{c} N_{c k}
$$

where $N_{k}^{*}$ is the design compressive axial force of member $k, N_{c k}$ is the nominal member capacity of the member $k$ in compression, and $\phi_{c}$ is the capacity reduction factor for compression.

The tension check is:

$$
N_{k}^{*} \leq \phi_{t} N_{t k}
$$

where $N_{k}^{*}$ is the design tensile force of member $k, N_{t k}$ is the nominal section capacity of the member $k$ in tension, and $\phi_{t}$ is the capacity reduction factor for tension. 


\section{Optimization formulation}

The objective of the design optimization is to determine the portal frame building having the minimum cost, while satisfying the design requirements. The cost of the main frame depends on frame spacing, pitch and cross-section sizes. The objective function can be expressed in terms of the cost per unit length of the building as follows:

$$
\text { Minimize } \mathrm{W}=\frac{1}{b_{f}} \sum_{i=1}^{n} w_{i} l_{i}
$$

where $W$ is the cost of main frame per unit length of building, $b_{f}$ is the frame spacing, $w_{i}$ are the cost $\mathrm{A}$ per unit length of cold-formed steel sections (Table 1), $l_{i}$ are the lengths of cold-formed steel structural members, and $n$ is the number of members.

The normalized forms of the design constraints or unity factors given in Equations (4)-(8) are expressed as follows:

$$
\begin{aligned}
& g_{1}=\frac{N_{k}^{*}}{\phi_{c} N_{s}^{k}}+\frac{M_{x k}^{*}}{\phi_{b} M_{b x}^{k}}-1 \leq 0 \\
& g_{2}=\frac{M_{s k}^{*}}{\phi_{b} M_{b}^{k}}-1 \leq 0 \\
& g_{3}=\frac{M_{k}^{*}}{\phi_{b} M_{s}^{k}}+\frac{V_{k}^{*}}{\phi_{v} V_{v k}}-1 \leq 0 \\
& g_{4}=\frac{N_{k}^{*}}{\phi_{c} N_{c k}}-1 \leq 0 \\
& g_{5}=\frac{N_{k}^{*}}{\phi_{t} N_{t k}}-1 \leq 0
\end{aligned}
$$

The design specification is the ultimate limit state (ULS) that constitutes the constraints for the optimization problem. Penalty functions are required to define the relationship between the objective function and constraints and to transform a constrained problem to an unconstrained one (Camp et al. 1998, Pezeshk et al. 2000). The relationship known as the fitness function often has the form:

$$
F=W[1+C]
$$

where $F$ is the fitness function, $W$ is the objective function, being the cost of frame per unit length of building, and $C$ is the constraint violation penalty.

In this research, the penalty value is assigned through the maximum level of violation of the unity-factor constraints in Equations (10a)-(10e) as follows:

$$
g=\max \left[g_{1}, g_{2}, g_{3}, g_{4}, g_{5}\right]
$$

In this article, penalty values are imposed empirically, in proportion to the severity of constraint violation. Through a numbers of trials, it is observed that two levels of violated constraints with the magnitudes as shown in Equation(13) are suitable to eliminate the violated solutions through 


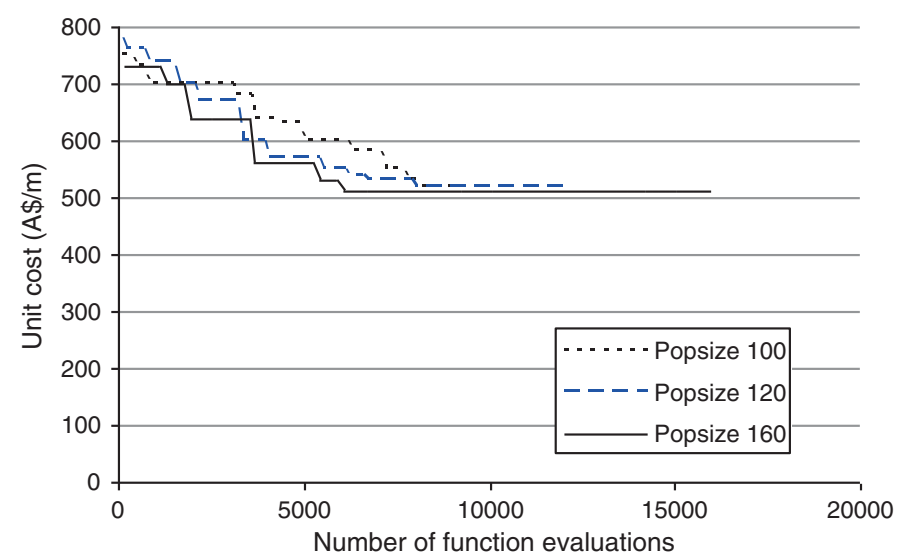

Figure 8. Progress of the GA for Frame A with fixed pitch and frame spacing.

the evolutionary process, as follows:

$$
C= \begin{cases}0 & \text { if } g \leq 0 \\ g & \text { if } 0<g \leq 0.5 \\ 10 g & \text { if } g>0.5\end{cases}
$$

The proposed optimization procedure aims to minimize the value of the fitness function $\mathrm{F}$ (Equation 11). This is achieved by minimizing the cost $W$ and reducing the penalty $C$ to zero. The procedure involves a real-coded GA, frame analysis and cold-formed steel design. As can be seen from Figure 8, the evaluation process computes the fitness function values using the objective function (Equation 9) along with the corresponding penalty values defined in Equation (13). Better (i.e. cheaper) solutions will yield smaller fitness values, and consequently are selected preferentially by the tournament selection operator. The criterion for terminating the program is a predefined total number of function evaluations. This criterion is suitable to investigate the convergence history of the algorithm.

\section{Real-coded genetic algorithm}

The characteristic of real-coded GAs is that genetic operators are directly applied to the design variables without coding and decoding as with binary GAs. Solving optimization problems using real-coded GAs is therefore less cumbersome when compared to the binary-coded GAs. The algorithm used in this article randomly generates a set of solutions known as the initial population. From this population, the next generation of solutions is evolved by conducting three genetic operations: selection, crossover and mutation. The flowchart of the real-coded GA used in this article is shown in Figure 7.

\subsection{Selection and elitism strategy}

In tournament selection operator, the process is conducted by picking at random two solutions from the current population to compare their fitness values. The solution with a better fitness value is selected for the next operation. The process of random selection ensures that the best solutions in the population will not dominate the mating pool, as in the proportional selection 
method. The diversity of the population is thus preserved to increase the exploration component of the algorithm.

The best individuals in the population, depending on the adopted percentage of population, are retained and carried forward unchanged to the next generation. The rest of the new population is created by the three genetic operators of selection, crossover and mutation applied to the entire current population including elite individuals.

\subsection{Real-coded crossover and mutation operators}

With real coding, the difficulty is how to use a pair of real-coded decision variable vectors to produce a new pair of offspring vectors or how to mutate a real decision variable vector in a meaningful manner (Deb 2001). In this article, the simulated binary crossover (SBX) (Deb and Agrawal 1995) and polynomial mutation (Deb 1997, Deb and Gulati 2001) are applied to create the new individuals for the next generation.

The SBX operator picks at random two solutions in the current population, known as parents, to create two offspring symmetrically to avoid a bias toward any particular parent solution in a single crossover operation. The formulation used for SBX is as follows:

$$
\begin{aligned}
& x_{i}^{(1, t+1)}=0.5\left[(1+\beta) x_{i}^{(1, t)}+(1-\beta) x_{i}^{(2, t)}\right] \\
& x_{i}^{(2, t+1)}=0.5\left[(1-\beta) x_{i}^{(1, t)}+(1+\beta) x_{i}^{(2, t)}\right]
\end{aligned}
$$

where $\beta$ is the probability distribution function for crossover, $x_{i}^{(1, t)}$ and $x_{i}^{(2, t)}$ are the parent solutions, and $x_{i}^{(1, t+1)}$ and $x_{i}^{(2, t+1)}$ are the children created for the next generation.

To ensure that the new values of the decision variable remain within the range $\left[x_{i}^{l}, x_{i}^{u}\right]$, where $x_{i}^{l}$ and $x_{i}^{u}$ are the lower and upper bounds, respectively, the probability distribution for the crossover operator has the form:

$$
\beta\left(\eta_{c}\right)= \begin{cases}{[\alpha u]^{1 /\left(\eta_{c}+1\right)}} & \text { if } u \leq 1 / \alpha \\ {[1 / 2-\alpha u]^{1 /\left(\eta_{c}+1\right)}} & \text { if } 1 / \alpha<u \leq 1\end{cases}
$$

where $u$ is a random number between 0 and $1, \eta_{c}$ is the distribution index for crossover, $\alpha=$ $2-\chi^{-\left(\eta_{c}+1\right)}$, and $\chi$ is calculated as follows:

$$
\chi=1+\frac{2}{x_{i}^{(2, t)}-x_{i}^{(1, t)}} \min \left[\left(x_{i}^{(1, t)}-x_{i}^{l}\right),\left(x_{i}^{u}-x_{i}^{(2, t)}\right)\right] ; \text { assuming } x_{i}^{(1, t)}<x_{i}^{(2, t)}
$$

Like in the SBX operator, polynomial mutation also uses probability distribution $\bar{\delta}\left(\eta_{m}\right)$, being a polynomial function to create the child solution in the vicinity of a parent solution. The formulation for the mutation operator (Deb 1997, Deb and Gulati 2001) has the form:

$$
y_{i}^{(1, t+1)}=x_{i}^{(1, t+1)}+\left(x_{i}^{u}-x_{i}^{l}\right) \bar{\delta}
$$

where $x_{i}^{u}$ and $x_{i}^{l}$ are the boundaries of decision variables, and $y_{i}^{(1, t+1)}$ is a new solution obtained from the mutation operator.

To ensure that no solution would be created outside the range of $x_{i}^{u}$ and $x_{i}^{l}$ (Deb and Gulati 2001), the parameter $\bar{\delta}\left(\eta_{m}\right)$ has the following form:

$$
\bar{\delta}= \begin{cases}{\left[2 u+(1-2 u)(1-\delta)^{\eta_{m}+1}\right]^{1 /\left(\eta_{m}+1\right)}-1} & \text { if } u \leq 0.5, \\ 1-\left[2(1-u)+2(u-0.5)(1-\delta)^{\eta_{m}+1}\right]^{1 /\left(\eta_{m}+1\right)} & \text { if } 0.5<u \leq 1\end{cases}
$$

where $u$ is a random number between 0 and $1, \eta_{m}$ is the distribution index for mutation, and $\delta=\min \left[\left(x^{(1, t+1)}-x_{i}^{l}\right),\left(x_{i}^{u}-x^{(1, t+1)}\right)\right] /\left(x_{i}^{u}-x_{i}^{l}\right)$. 
601

602

603

604

605

606

607

608

609

610

611

612

613

614

615

616

617

618

619

620

621

622

623

624

625

626

627

628

629

630

631

632

633

634

635

636

637

638

639

640

641

642

643

644

645

646

647

648

649

650

In this article, $\eta_{m}=\eta_{c}=1$ is used. A technique that rounds off the number in dealing with discrete design variables is used in case SBX crossover or polynomial mutation create decimal numbers. Constant probabilities are assigned to both crossover and mutation operators to reduce the possibility of destroying the good solutions. Based on a number of trials, a crossover probability $P_{c}$ of 0.9 was used throughout in this study. It was observed that premature convergence happened with a low mutation probability. To increase the GA's exploration capacity in the solution space to increase the chance of locating the optimum solution, the mutation probability $P_{m}$ is tuned empirically as high as 0.1 .

\section{Design examples}

\subsection{Frame A with fixed topology}

\subsubsection{Exhaustive enumeration}

Frame A, without knee braces, in which the pitch is $10^{\circ}$ and frame spacing is $4 \mathrm{~m}$, is considered. Such a typical pitch and frame spacing are commonly used for cold-formed steel portal frames. This design problem has two discrete decision variables. The optimum cross-sections for the columns and rafters can be determined from the cross-sections shown in Table 1 by exhaustive enumeration using the LGSFrame as mentioned in Section 2.4. As can be seen from the list of cold-formed steel channel-sections, there are 40 options of cold-formed cross-sections used for members, including both single sections (C) and back-to-back channel-sections (BBC).

Four designs satisfied the member checks. These design options are shown in Table 4. As can be seen, the smallest unit cost obtained is A $\$ 513 / \mathrm{m}$ with back-to-back channel-section BBC30030 for both columns and rafters. This result will be used to validate the proposed real-coded GA for searching the optimum solution. It is observed that all design constraints, i.e. the member checks, are satisfied. The critical constraint relating to combined axial compression and bending moment for rafters governs the design in the case of ultimate load combination ULC3, with the unity factor being 0.9 against the upper limit of 1.0 .

\subsubsection{Real-coded GA}

The real-coded GA is used to determine the optimum cross-sections for the members of Frame A as discrete variables, from the 40 alternative cross-sections for members as mentioned above. The design process (Figure 7) is repeated with three different population sizes to investigate the possibility of reaching the optimum solution. The convergence histories obtained from the GA are depicted in Figure 8. As can be seen, the fitness function converged within 5500 function evaluations. The three runs in the optimization process lead to the same minimum-cost solution as the exhaustive enumeration process. This result proves the reliability of the proposed GA with real-coded parameters.

Table 4. Optimum cross-sections for Frame A with fixed topology.

\begin{tabular}{lccccccc}
\hline Column section & Rafter section & $g_{1}$ & $g_{2}$ & $g_{3}$ & $g_{4}$ & $g_{5}$ & $W(\mathrm{~A} \$ / \mathrm{m})$ \\
\hline BBC30030 & BBC30030 & -0.30 & -0.28 & -0.32 & -1.0 & -1.0 & 513 \\
BBC35030 & BBC30030 & -0.32 & -0.30 & -0.35 & -1.0 & -1.0 & 547 \\
BBC30030 & BBC35030 & -0.35 & -0.45 & -0.59 & -1.0 & -1.0 & 599 \\
BBC35030 & BBC35030 & -0.44 & -0.41 & -0.58 & -1.0 & -1.0 & 633 \\
\hline
\end{tabular}




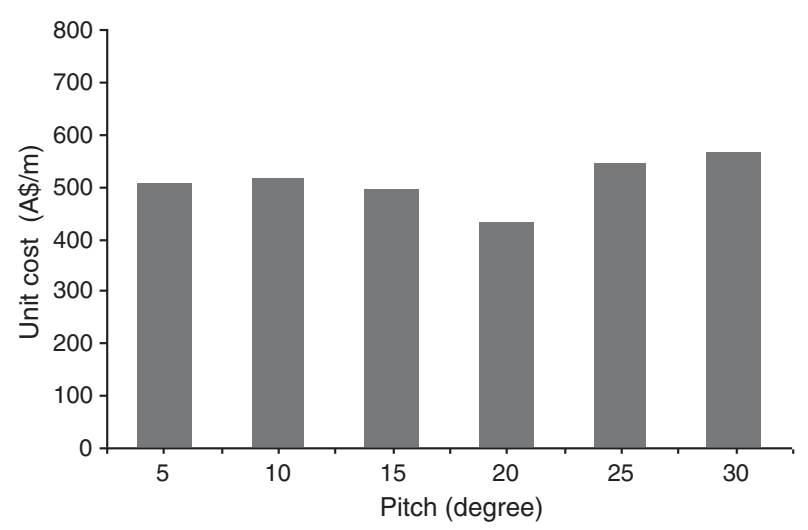

Figure 9. Effect of pitch on unit cost of Frame A with fixed frame spacing.

\subsection{Frame A with variable pitch}

\subsubsection{Exhaustive enumeration}

To validate the capacity of the proposed GA in solving a more complicated problem as the effect of pitch is taken into account, the process of exhaustive enumeration is carried out manually. In this case, the pitch is varied from $5^{\circ}$ to $30^{\circ}$ in increments of $5^{\circ}$ to investigate its effect. The frame spacing is fixed at $4 \mathrm{~m}$. For each pitch, the optimum cross-sections for members of Frame A are determined through exhaustive enumeration by using the LGSFrame program manually. The influence of pitch on the cost per unit length of building is shown in Figure 9. It can be seen that the pitch has a clear influence on the cost of portal frame building. The minimum unit cost obtained is $\mathrm{A} \$ 432 / \mathrm{m}$, with a pitch of $20^{\circ}$ and cross-sections of BBC30024. However, the constraint of combined axial compression and bending for the rafter check was violated by $g_{1}=0.006$. The logical inference from this result is that the cheapest feasible design can be expected to have a pitch close to $20^{\circ}$.

\subsubsection{Real-coded $G A$ with fixed frame spacing and variable pitch}

The optimum pitch and cross-sections for the members of Frame A are determined again using the real-coded GA with a fixed frame spacing of $4 \mathrm{~m}$. In this case, the pitch is processed as a continuous variable varied in the range of $\left[5^{\circ}, 90^{\circ}\right)$, while cross-sections are discrete, selected from the list (Table 1). The design process is also repeated with three different population sizes. The progress of the GA is shown in Figure 10. As can be seen, the minimum unit cost achieved from GA is found to be $\mathrm{A} \$ 433 / \mathrm{m}$ with a pitch of $20.5^{\circ}$ and cross-section of $\mathrm{BBC} 30024$ for both columns and rafters. As expected, the unit cost obtained from the GA is a bit larger than the infeasible solution with a pitch of $20^{\circ}$ from exhaustive enumeration because the GA solution is feasible. The design constraint for the rafter becomes active in the case of the combined actions of axial compression and moment. Again, this demonstrates that real-coded GA is an effective and reliable method to find the optimum pitch and cross-sections of members in portal frame design.

In addition to the exhaustive enumeration carried out in Subsection 5.2.1, the GA is verified further here by generating the maximum cost feasible design based on a fixed frame spacing of $4 \mathrm{~m}$ and variable pitch. To maximize the cost, it is sufficient to multiply the objective function (Equation 9) by -1.0. A population of 100 was used and a total of five random runs of the GA was carried out, with a maximum of 15,000 function evaluations per run. 


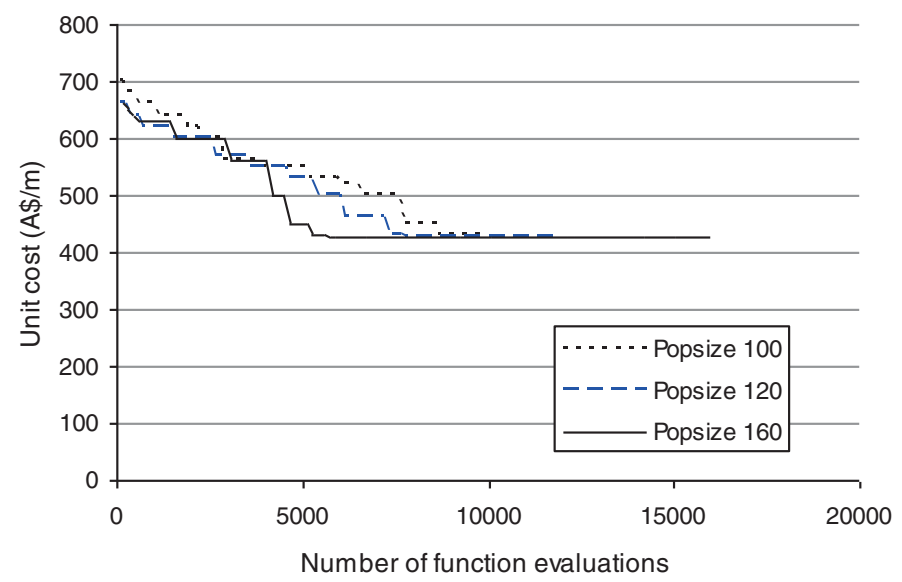

Figure 10. GA progress for Frame A with fixed frame spacing.

The maximum cost obtained from RC-GA is A $\$ 728.5 / \mathrm{m}$ with a pitch of $35.5^{\circ}$. The size of both the columns and rafters is $\mathrm{BBC} 35030$, which is the largest and most expensive. Only the distortional bucking constraint on the rafter is binding $\left(g_{2}=0\right)$ under load combination ULC2. The other constraints are slack. This solution was achieved with three GA runs out of five.

The second most expensive solution also has the largest section of BBC35030 for both the columns and rafters. The cost and pitch are $\mathrm{A} \$ 725 / \mathrm{m}$ and $35^{\circ}$, respectively. The critical constraint is also distortional buckling for the rafter with $g_{2}$ equal to 0.01 which is slightly higher than the best solution. Taken together with the cost and pitch, this suggests that this solution is a near optimum. This solution was achieved in one GA run out of five.

One GA run out of the five attempts failed to generate a good maximum cost solution. It is observed that the cost, pitch and section size for members obtained are $\mathrm{A} \$ 564 / \mathrm{m}, 30^{\circ}$ and section of BBC30030, respectively. Also, the distortional buckling constraint $\left(g_{2}=0.02\right)$ is active for rafter under load combination ULC2. This solution is self-evidently not a maximum, but it is still $30 \%$ more expensive than the lowest cost solution of $\mathrm{A} \$ 433 / \mathrm{m}$.

Therefore, it can be seen that four attempts out of five in total were successful in the sense that the two solutions found in these four attempts are both feasible and satisfactory in terms of the section sizes (i.e. the largest) with at least one binding constraint in each case. The maximum cost solution was obtained within 7200 function evaluations. The CPU time was 8.3 hours per GA run using a machine with a $1.86 \mathrm{GHz}$ processor and $1 \mathrm{~GB}$ memory. It may be noted that the maximum-cost solution is $68 \%$ more expensive than the corresponding minimum-cost solution.

\subsubsection{Real-coded GA with variable frame spacing and variable pitch}

In this example, a design optimization for Frame A that accounts for effects of both pitch and frame spacing is conducted, using real-coded GA. The pitch and frame spacing are processed as continuous variables. The progress of the optimization process is shown in Figure 11. As can be seen, the three runs of the optimization process converged to the same unit cost, within 7500 function evaluations. The optimum pitch and frame spacing for Frame A obtained from the algorithm are $21^{\circ}$ and $3 \mathrm{~m}$, respectively. The optimum cross-section for both the columns and rafters is $\mathrm{BBC} 25024$ and the unit cost is $\mathrm{A} \$ 355 / \mathrm{m}$. The design constraint for the combined actions of axial compression and bending on rafter is active, i.e. $g_{1}=0$.

It can be seen that when the portal frame design includes the pitch and frame spacing as decision variables, the optimum frame obtained is cheaper than an optimum frame with fixed frame spacing 


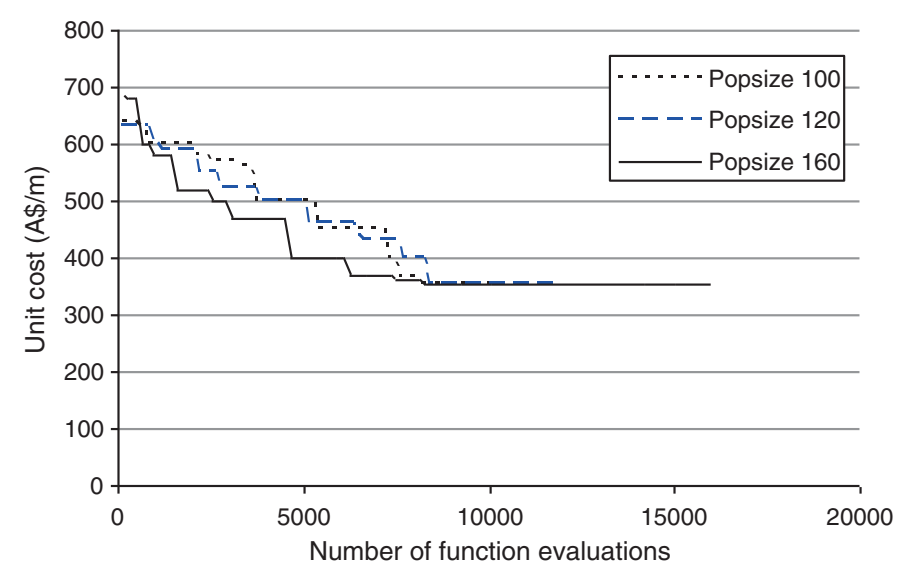

Figure 11. GA progress for Frame A with variable pitch and frame spacing.

$(18 \%)$ or fixed pitch $(31 \%)$. This demonstrates the benefit of topology optimization covering both pitch and frame spacing. It should be emphasized that the above-mentioned cost savings relate to the typical frame geometry, and not to previously optimized results described in the literature; the latter are not available, to the authors' knowledge.

\subsection{Frame $B$ with fixed pitch and fixed frame spacing}

In this example, the design optimization of Frame B having knee braces with a fixed pitch is considered using the real-coded GA. The pitch is fixed as $10^{\circ}$ and the frame spacing is prespecified as $4 \mathrm{~m}$. In this problem, the optimum cross-sections for the columns, rafters and knee braces are again to be selected from the aforementioned list of 40 cold-formed cross-sections that include both single and back-to-back channel-sections (Table 1).

The population size of 160 individuals is used for determining the optimum cross-sections for members, since it has been proven in the previous sections to be the appropriate size to search for the optimum solution. The maximum permitted number of function evaluations is set at 8000 . The optimum cross-sections and corresponding unit costs are given in Table 5. The design constraint of knee brace buckling becomes active from load combination ULC2.

Thus, for the specified pitch of $10^{\circ}$ and frame spacing of $4 \mathrm{~m}$, Frame A, which does not have knee braces at the eaves, is $19.8 \%$ more expensive than Frame B, which has knee braces.

\subsection{Frame $B$ with variable pitch and variable frame spacing}

The optimum design of Frame B, taking into account the effect of pitch and frame spacing simultaneously, is considered in this example. There are five design decision variables in this problem: pitch and frame spacing, considered as continuous variables; and column, rafter and knee brace cross-sections as discrete variables. This optimization problem is more complicated

Table 5. Optimum cross-sections for Frame B with fixed topology.

\begin{tabular}{lccccccc}
\hline Member type & Cold-formed steel sections & $g_{1}$ & $g_{2}$ & $g_{3}$ & $g_{4}$ & $g_{5}$ & $W(\mathrm{~A} \$ / \mathrm{m})$ \\
\hline Column & BBC 30024 & -0.18 & -0.31 & -0.12 & -1.00 & -1.00 & 428 \\
Rafter & BBC 30024 & -0.12 & -0.13 & -0.10 & -1.00 & -1.00 & \\
Knee brace & C 20015 & -1.00 & -1.00 & -1.00 & 0 & -0.34 & \\
\hline
\end{tabular}


801

802

803

804

805

806

807

808

809

810

811

812

813

814

815

816

817

818

819

820

821

822

823

824

825

826

827

828

829

830

831

832

833

834

835

836

837

838

839

840

841

842

843

844

845

846

847

848

849

850

Table 6. Optimum solution for Frame B with variable topology.

\begin{tabular}{lccccccccc}
\hline Member type & Cold-formed steel sections & $g_{1}$ & $g_{2}$ & $g_{3}$ & $g_{4}$ & $g_{5}$ & $\theta_{f}$ & $b_{f}(\mathrm{~m})$ & $W(\mathrm{~A} \$ / \mathrm{m})$ \\
\hline Column & BBC 25024 & -0.01 & -0.03 & -0.09 & -1.00 & -1.00 & $17.5^{\circ}$ & 4.0 & 270 \\
Rafter & BBC 25024 & 0 & -0.01 & -0.07 & -1.00 & -1.00 & & & \\
Knee brace & C 20015 & -1.00 & -1.00 & -1.00 & -0.02 & -0.38 & & & \\
\hline
\end{tabular}

Table 7. Near-optimum solution for Frame B with variable topology.

\begin{tabular}{lccccccccc}
\hline Member type & Cold-formed steel sections & $g_{1}$ & $g_{2}$ & $g_{3}$ & $g_{4}$ & $g_{5}$ & $\theta_{f}$ & $b_{f}(\mathrm{~m})$ & $W(\mathrm{~A} \$ / \mathrm{m})$ \\
\hline Column & BBC 30030 & 0 & -0.06 & -0.04 & -1.00 & -1.00 & $17^{\circ}$ & 7.6 & 283 \\
Rafter & BBC 30030 & -0.02 & -0.08 & -0.07 & -1.00 & -1.00 & & & \\
Knee brace & BBC 10015 & -1.00 & -1.00 & -1.00 & -0.05 & -0.22 & & & \\
\hline
\end{tabular}

than previous examples as there are more design variables and the solution space is larger. The population size is selected as 160 and the number of function evaluations for terminating the program is 12,800 , equivalent to 80 generations. In such a complicated case, it was observed that the CPU time for solving the optimization problem was 7 hours, for a machine with processor speed of $1.86 \mathrm{GHz}$ and memory of $1 \mathrm{~GB}$.

Accordingly, the real-coded GA was run 10 times. It was observed that six out of 10 runs generate the same optimum solution. The combined action of bending moment and axial compression on the rafter is active $\left(g_{1}=0\right)$ in the case of load combination ULC2. The optimum unit cost obtained is A $\$ 270 / \mathrm{m}$ with corresponding parameters as shown in Table 6 . This result is $37 \%$ lower than Frame B having fixed topology and $24 \%$ lower than Frame A with both optimum pitch and frame spacing. The effect of knee braces reduces the optimum pitch by $3^{\circ}$ compared with the optimum pitch of the frame without knee braces.

It is interesting to note that the unit cost obtained from four out of 10 runs is $A \$ 283 / \mathrm{m}$, which is $4.8 \%$ more expensive than the optimum design for Frame B, with larger frame spacing and crosssections. In this case, the critical design constraint for combined bending and axial compression for the column becomes active. Such a solution may be suitable for a building that requires a larger frame spacing (Table 7).

\section{Conclusions}

The real-coded GA was developed to minimize the cost per unit length of a cold-formed steel portal frame building with different frame spacings and topologies, based on the Australian code of practice for cold-formed steel. The influence of a knee brace at the eaves on the optimum topology and unit cost was also considered. The real-coded GA program has been developed to determine the optimum topology and the most suitable cross-sections for members simultaneously. The frame obtained from the proposed algorithm can be considered as the most economical design in each case, since the critical design constraint in all examples becomes active. The reliability and robustness of the algorithm have been demonstrated. In addition, the high consistency of the optimum results was achieved through a number of trials for minimizing the objective function. However, the time for solving the optimization problem is still large.

In the case of optimization problems having many design variables, both optimum and nearoptimum solutions were obtained. Through five design examples, it was shown that the real-coded GA is very efficient in handling the optimization problems having both continuous and discrete variables. Although the cost is calculated based on material used for the main frames, the reduction 
is very remarkable when the optimum topology is reached. It is also shown that frames having

\section{Acknowledgements}

The financial support from the Queen's University Belfast is gratefully acknowledged.

\section{References}

Allwood, R.J. and Chung, Y.S., 1984. Minimum weight design of trusses by an optimality criteria method. International Journal of Numerical Methods in Engineering, 20, 697-713.

Australian/New Zealand Standard ${ }^{\mathrm{TM}}$, 2002a. AS/NZS 1170-0. Structural design actions_Part 0: General principles.

Australian/New Zealand Standard ${ }^{\mathrm{TM}}$, 2002b. AS/NZS 1170-1. Structural design actions-Part 1: Permanent, imposed and other actions.

Australian/New Zealand Standard ${ }^{\mathrm{TM}}$, 2002c. AS/NZS 1170-2. Structural design actions-Part 2: Wind actions.

Australian/New Zealand Standard ${ }^{\mathrm{TM}}$, 2005. AS/NZS 4600:2005. Cold-formed steel structures.

Camp, C., Pezeshk, S., and Cao, G., 1998. Optimum design of two dimensional structures using genetic algorithm. Journal of Structural Engineering ASCE, 124 (5), 551-559.

Chen, T.Y. and Chen, C.J., 1997. Improvement of simple genetic algorithm in structural design. International Journal of Numerical Methods in Engineering, 40, 1323-1334.

Chen, Y. and Hu, K., 2008. Optimal design of steel portal frames based on genetic algorithms. Journal of Architecture and Civil Engineering China, 2 (4), 318-322.

Deb, K., 1997. Mechanical component design using genetic algorithms. In: D.-Dasgupta and Z. Michalewicz, eds.Evolutionary algorithms in engineering applications. New York: Springer, 495-512.

Deb, K., 2001. Multi-objective optimization using evolutionary algorithms. Chichester: John Wiley and Sons.

Deb, K. and Agrawal, R. B., 1995. Simulated binary crossover for continuous space. Complex Systems, 9 (2), $115-148$.

Deb, K. and Gulati, S., 2001. Design of truss-structures for minimum weight using genetic algorithms. Finite Element in Analysis and Design, 37, 447-465.

Erbatur, F. and Al-Hussainy, M.M., 1992. Optimum design of frames. Joumal of Computers and Structures, 45 (5), 887-891.

Gero, M.B.P., García, A.B., and del Coz Díaz, J.J., 2005. A modified elitist genetic algorithm applied to the design optimization of complex steel structures. Journal of Constructional Steel Research, 61 (2), 265-280.

Gero, M.B.P., García, A.B., and del Coz Díaz, J.J., 2006. Design optimization of 3D steel structures: genetic algorithms vs. classical techniques. Journal of Constructional Steel Research, 62 (12), 1303-1309.

Goldberg, D.E., 1989. Genetic algorithms in search, optimization and machine learning. New York: Addison-Wesley.

Hernández, S., et al., 2005. Design optimization of steel portal frames. Joumal ofAdvances in Engineering Software, 36, $626-633$.

Holland, J.H., 1975. Adaptation in natural and artificial systems. Ann Arbor, MI: University of Michigan Press.

Issa, H.K. and Mohammad, F.A., 2010. Effect of mutation schemes on convergence to optimum design of steel frames. Journal of Constructional Steel Research, 66 (7), 954-961.

Kameshki, E. and Saka, M.P., 2001. Optimum design of nonlinear steel frames with semi-rigid connections using a genetic algorithm. Journal of Computers and Structures, 79, 1593-1604.

Kirk, P., 1986. Design of a cold-formed section portal frame building system. In: W.W.Yuand J.H. Senne, eds. Proceedings of the 8th international specialty conference on cold-formed steel structures, 11-12 November 1986 St Louis. Missouri: University of Missouri-Rolla, 295-310.

Kuhn, H.W. and Tucker, A.W., 1951. Nonlinear programming. In: Proceedings of the 2nd Berkeley symposium on mathematics, statistics and probability, 31 July-8 August 1950 Berkeley. Berkeley: University of California Press, 481-492.

Michalewicz, Z., 1992. Genetic algorithms + data structures = evolution programs. Berlin: Springer.

Moses, F., 1964. Optimum structural design using linear programming. Journal of Structural Engineering ASCE, 90 (6), 89-104.

Ono, I. and Koframeashi, S., 1997. A real-coded genetic algorithm for function optimization using unimodal normal distribution crossover. In: Proceedings of the 7th international conference on genetic algorithms, 19-23 July 1997. St Louis, MO: Morgan Kaufmann, 246-253.

Pezeshk, S., Camp, C., and Chen, D., 2000. Design of nonlinear framed structures using genetic optimization. Journal of Structural Engineering ASCE, 126 (2), 382-388. 
901 Rhodes, J. and Burns, R., 2006. Development of a portal frame system on the basis of component testing. In: Proceedings of the 18th international specialty conference on cold-formed steel structures, 25-27 October 2006 Missouri. Missouri: University of Missouri-Rolla, 367-385.

Saka, M.P., 2003. Optimum design of pitched roof steel frames with haunched rafters by genetic algorithm. Journal of Computers and Structures, 81, 1967-1978.

906

Toropov, V.V., and Mahfouz, S.Y., 2001. Design optimization of structural steelwork using genetic algorithm, FEM and a system of design rules. Journal of Engineering Computations, 18 (3/4), 437-459.

Wright, A.H., 1991. Genetic algorithms for real parameter optimization. In: Foundations of genetic algorithms 1(FOGA-1).

908

909

910

911

912

913

914

915

916

917

918

919

920

921 